\title{
A geochemical and statistical approach for assessing heavy metal pollution in sediments from the southern Caspian coast
}

\author{
${ }^{1 *}$ A. Parizanganeh; ${ }^{2}$ V. C. Lakhan; ${ }^{1}$ H. Jalalian \\ ${ }^{1}$ Department of Geography, Zanjan University, P. O. Box 45195-313, Zanjan, Iran \\ ${ }^{2}$ Department of Earth Sciences, University of Windsor, Windsor, Ontario, Canada N9B 3P4 \\ Received 6 August 2006; revised 26 February 2007; accepted 7 March 2007; available online 20 June 2007
}

\begin{abstract}
The nearshore marine environment of the Caspian sea is a major repository for toxic metals originating from various sources. Since the persistent toxic metals pose serious health risks this research concentrated on investigating the concentrations and spatial distribution of metals in the nearshore sediments along the Iranian coast of the Caspian sea. Fourteen sampling sites were selected along the coast and approximately $400 \mathrm{~g}$ of surficial sediments were obtained. Samples were sieved and three grain size fractions from each sample plus fourteen bulk samples were selected for the analysis of metals. Laboratory analysis of the samples utilized the Cold Acetic protocol, followed by Inductively coupled plasma optical emission spectroscopy. The statistical techniques were used to analyze all obtained data. Linear regression analysis demonstrated that grain size of the sediments was not a major factor controlling the concentrations and spatial distributions of heavy metals. Box and Whisker plots emphasized that metal concentrations were not homogeneously distributed. Discriminant analysis was also proved to be useful in identifying geographic areas where heavy metal concentrations occur along the coast.
\end{abstract}

Key words: Caspian sea, discriminant analysis, heavy metals, marine environment, nearshore sediments

\section{INTRODUCTION}

Metals discharged into nearshore areas of marine environments are likely to be scavenged by particles and removed to the sediments. The sediments, therefore, become large repositories of toxic heavy metals. While sediment contamination by trace metals in marine areas has received increased global attention by investigators (Fatima, et al., 1988; Ryan and Windom, 1988; Subramanian and Mohanachandran, 1990; Ergin, 1991; Din, 1994; McMurtry, et al., 1995; De Gregori, et al., 1996; Balls, et al., 1997; Buchholtz, et al., 1997; Uriarte, et al.,1998; Çelo, et al., 1999; Zhang, et al., 2001; Zabetoglou, et al., 2002; Lakhan, et al., 2002; Caccia, et al., 2003; Che, et al., 2003; Chen, et al., 2004; Santos, et al., 2005), there is, nevertheless, very limited research on concentrations of heavy metals in the nearshore environment of the Caspian sea. Previous investigations have documented the accumulation of contaminants in Caspian sea fish populations (Kijawara, et al., 2002; Anan, et al., 2002; Kijawara, et al., 2003; Agusa, et al., 2004), the concentrations of

\*Corresponding Author Email: zanganeh_h@yahoo.com Tel./Fax: +98241 4269056 metals (De Mora, et al., 2004a), organochlorinated compounds (De Mora, et al., 2004b) and aliphatic and aromatic hydrocarbons (Tolosa, et al., 2004) in Caspian sea sediments. Since pollutants incrementally accumulate in the landlocked Caspian sea, it is necessary to gain insights on the concentrations and spatial distribution of toxic metals in the Caspian sea marine environment. This paper examined metal concentrations in nearshore sediments from the Iranian coast of the Caspian sea.

\section{Brief remarks on the studied area}

The Iranian coast of the Caspian sea stretches for nearly $700 \mathrm{~km}$ from Azerbaijan in the west to Turkmenistan in the east (Fig. 1). This coastline is now becoming increasingly polluted with massive loads of contaminants discharged into the Caspian sea from various anthropogenic sources. Motavalli (1999) reported that the World Bank estimated that a million cubic meters of untreated industrial wastewater is discharged directly into the Caspian, with the bulk coming from oil and mining operations. The Volga River is one of the major contributors of a wide variety of industrial 
and agricultural contaminants collected from its extensive river basin. The report by Neville mentioned scientific estimates of annual average discharges of 60,000 metric tonnes of petroleum byproducts, 24,000 tonnes of sulfites, and 400,000 tonnes of chlorine. Given the fact that the Caspian is a non-tidal sea and is land locked, the bulk of the discharged contaminants remain trapped within its basin. Sea currents transport and circulate the entrapped pollutants along the Iranian coast of the Caspian Sea. A large percentage of the more than 10 million people who reside in the Iranian coastal provinces bordering the Caspian Sea are therefore exposed to high concentrations of toxic contaminants. For instance, coastal residents regularly eat sturgeon and other fish from the Sea.

The pollutants accumulating in the fish, especially the sturgeon (Agusa, et al., 2004) are transferred to the human food chain. Questions have been raised as to whether the higher rates of cancer recorded in the study area could be associated with fish consumption. Other than having detrimental impacts on human health, several studies have also reported that pollution and contamination are contributing factors to the precipitous decline in sturgeon catch from the Caspian sea. According to the Caspian Environmental Program web site (http://www.caspianenvironment.org/newsite/ Caspian-EnvironmentalIssues.htm), sturgeon landings have decreased from 30,000 tonnes in 1985 to only 5,672 tonnes in 1995 . Here it should be emphasized that 85 to $90 \%$ of the world's sturgeon fish is obtained from the Caspian sea which yields approximately $95 \%$ of the world's black caviar. The decline in sturgeon catch is not only threatening the survival of the caviar industry, but also affecting the domestic economy in Iran.
Ecosystems, especially in the nearshore marine environment of the Iranian coast, are now under severe stresses from the cumulative impacts of a mixture of highly toxic contaminants. Marine flora and fauna are threatened, and being decimated. One example of detrimental impacts on aquatic life could be found in the account by the Energy Information Administration (2003) which reported that thousands of seals that live in the Caspian sea have died since 2000 because of the consequences of pollution that affected their immune systems. The existing and potential problems to aquatic and human life from toxic pollutants, therefore, requires investigating the current concentrations of contaminants in the studied area.

\section{MATERIALS AND METHODS}

\section{Sampling procedures}

Fourteen sampling sites (S1 to S14), approximately $50 \mathrm{~km}$ apart were selected from the nearly $700 \mathrm{~km}$ long Iranian coast of the Caspian sea ( Fig. 1). The sites were located in the vicinity of settled areas, with these being Astara (S1), Lisar (S2), Taze abad (S3), Hasan Rud (S4), Dastak (S5), Gaskar mahale (S6), Tonkabon (S7), Hachi Rud (S8), Vanosh (S9), Siah kola (S10), Zarinabad (S11), Amirabad (S12), Gamishtapeh (S13), and Makhdomgholi (S14). A standard Van Veen grab, with grasping area of $250 \mathrm{~cm}^{2}$, was used in the third week of August 2004 to obtain approximately $400 \mathrm{~g}$ of surficial sediments from the lower foreshore area. Each of the fourteen samples was collected at approximately $0.3 \mathrm{~m}$ away from the still water-shore interface of the Caspian sea. Care was taken to collect only the top 1 $\mathrm{cm}$ of sediment from each of the sites. Samples were placed in plastic containers and then frozen.

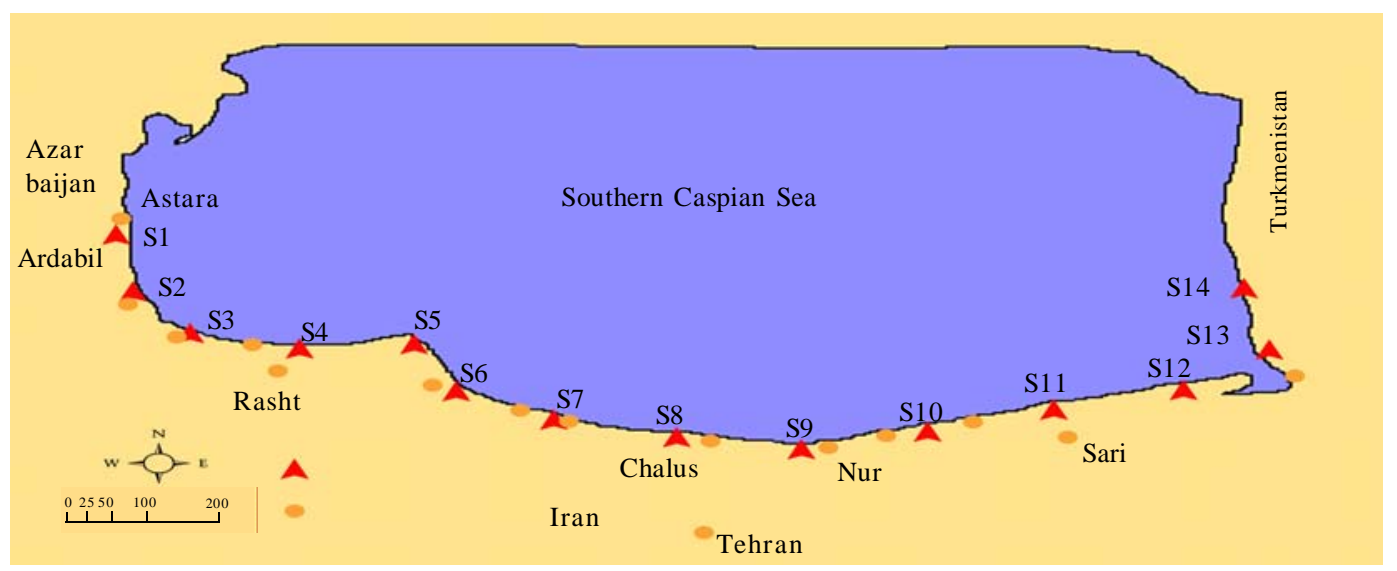

Fig. 1: Location of sampling sites along the Iranian coast of the Caspian Sea 
Samples were subsequently dried at $110{ }^{\circ} \mathrm{C}$ in a Gallenkamp OV-160 oven. A Mettler PC 4400 balance was then used to obtain $100 \mathrm{~g}$ of sediment from each of the fourteen samples. For granulometric composition determination the dried samples were separated into particle size fractions using ten sieves. The sieves (1.7 $\mathrm{mm}, 1 \mathrm{~mm}, 0.5 \mathrm{~mm}, 0.355 \mathrm{~mm}, 0.25 \mathrm{~mm}, 0.212 \mathrm{~mm}, 0.125$ $\mathrm{mm}, 0.075 \mathrm{~mm}, 0.053 \mathrm{~mm}$ and $0.025 \mathrm{~mm}$ ) were shaken with a Tyler ROTAP. Grain size plots and moment statistics were obtained with the Statistica for Windows software (StatSoft, 1997). Based on the grain size plots and the cumulative weight of sediments in the ten sieves, it was decided to analyze, for heavy metals, the grain size fractions $(0.355 \mathrm{~mm}, 0.212 \mathrm{~mm}$ and $0.075 \mathrm{~mm})$ which had the most weight in the sieves. The finer fractions $(0.053$ $\mathrm{mm}$ and $0.025 \mathrm{~mm}$ ) were not analyzed because only three of the fourteen samples comprised fine-grained sediments. To consider all grain sizes, fourteen bulk samples were also analyzed for heavy metals. The three grain size fractions plus the bulk samples provided a total of 56 samples for the analysis of heavy metals. While each sample was analyzed for the presence of 18 metals (Al, As, Bi, Ca, Cd, Co, Cr, Cu, Fe, K, Mg, Mn, Na, $\mathrm{Ni}, \mathrm{Pb}, \mathrm{Sb}, \mathrm{V}$ and $\mathrm{Zn}$ ), this paper presents results on measurable concentrations of the heavy metals, $\mathrm{Al}, \mathrm{Cd}$, $\mathrm{Cu}$. Ni, Pb and $\mathrm{Zn}$ in sediments of the southern part of Caspian coast in Iran.

\section{Laboratory preparation of samples}

The laboratory preparation of the samples involved the utilization of the cold acetic acid extraction protocol established by the Great Lakes Institute for Environmental Research (GLIER, 1996), University of Windsor. For each sample, this protocol required: 1 ) weighing $0.5 \mathrm{~g}$ of sediments and placing into a $30 \mathrm{~mL}$ pre-washed centrifuge tube; 2) adding $20 \mathrm{~mL}$ of 5\% Acetic acid (Anlar) into centrifuge tube, and capping loosely for $10 \mathrm{~min}$ to allow for gases, if any, to evolve. Cap tightly thereafter; 3) shaking each sample for $24 \mathrm{~h}$ at room temperature; 4) centrifuging each sample at $500 \mathrm{rpm}$ for $10 \mathrm{~min}$; 5) rinsing Whatman \# 4 filter paper two times with $1 \% \mathrm{HNO}$, three times with MQ and three times with 5\% Acetic acid. Allow filter paper to drip dry; 6) filtering contents of the tube, and taking precaution not to rinse the filter paper; 7) recording weight of filtrate (Acetic in centrifuge tube); 8) makingup the solution with the use of MQ to $50 \mathrm{~g}$ by weight measured to the nearest $0.01 \mathrm{~g}$ exercising care to keep pre-weighted bottle very dry during handling to avoid added error to the solution's final weight.
Quality control procedures and metal determinations

Quality control for sample analysis followed procedures established by GLIER(1996). Quality control for each batch of analyzed sample was strictly maintained by placing among the sample set three method blanks, two samples in duplicate, one tissue internal reference pool, and two Certified Reference Materials (Mess-3, LKSD-4). Metal concentrations in the sediment samples were determined by Inductively Coupled Plasma Optical Emission Spectroscopy, IRIS \# 701776 (Thermo Jarrell Ash Corporation). The detection limits ( $\mu \mathrm{g} / \mathrm{g})$, based on the cold acetic protocol, for each of the metals to be discussed were: A1 10.7, Cd 0.2, Cu 0.8, Ni 0.8, Pb 1.7 and Zn $0.2 \mu \mathrm{g} / \mathrm{g}$.

\section{RESULTS}

\section{Graphical observations}

The results provided evidence of large differences in total metal concentrations in the sediment samples from the fourteen sites. Before explaining the reasons for the spatial variations in heavy metal contaminants along the coast, some general remarks will be provided on graphical observations. Box and Whisker plots (Fig. 2 a to $f$ ) of the combined bulk and grain size fractions demonstrated that all metals have significant concentrations, with pronounced concentrations of some metals at specific sites and in different geographic areas. In the west at sites 1 to 3 , near to the Azerbaijan border, elevated concentrations of $\mathrm{Al}, \mathrm{Cd}, \mathrm{Cu}$ and $\mathrm{Ni}$ could be found. The median concentrations of all metals were also comparatively high at sites 5 and 6 . With the exception of $\mathrm{Cd}$, the median concentrations of all metals remained fairly consistent in the geographic area stretching from sites 7 to 12 . This was followed by a noticeable increase in metal concentrations at site 13. At site 14 , on the eastern edge of the coast near to the Turkmenistan border, all metals had high median concentrations.

\section{Statistical analyses}

Since several previous and many more recent studies (Lin, et al., 2002; Huang and Lin, 2003; Lakhan, et al., 2003; Gorenc, et al., 2004) found the grain size of sediments to be a significant variable that controls or influences the spatial distribution and concentrations of heavy metals in the environment, correlation and regression analyses were performed to determine the likelihood of grain size influencing the observed spatial variability of heavy metal concentrations along the coast. Without presenting the full correlation and regression 
results, it should be noted that when the six metals were correlated with the different grain size fractions it was observed that the grain size of the sediments did not have a noticeable pronounced effect on the spatial distribution of heavy metals. One reason for this occurrence could be the fact that the analyzed grain sizes were not in the very fine material range $(<0.063$ $\mathrm{mm}$ ) which numerous investigators (for example, Förstner, et al.,1982; Cauwet, 1987; Arujo, et al., 1988; Chakrapani and Subramanian, 1993; Maurer, et al., 1994; De Gregori, et al., 1996; Ujevi, et al., 2000; Zhang, et al., 2001; Avila-Perez, et al., 2002; Che, et al., 2003) found to be associated with the highest concentrations of heavy metals. In addition to correlation and regression analysis, discriminant analysis was used to investigate whether the spatial variations of the various metals along the coast had statistically significant concentrations in specific (i.e., localized) or well-defined geographic areas. Details on discriminant analysis can be found in several studies (for example, Johnston, 1992; Huberty, 1994; McLachlan, 2004), and applications of the technique to the study of heavy metal concentrations in the coastal environment have been presented by Lakhan, et al., (2002, 2003). The discriminant analysis module in the Statistical Package for the Social Sciences, version 13 (SPSS, Inc., 2003) was used to assess the statistical uniqueness of metal concentrations at each of the sample sites. Since discriminant analysis was used to establish the differences between or among sample sites, the fourteen sample sites (S1 to S14) were entered as the grouping variable. The six heavy metal concentrations were entered as independent variables. The program was executed for each of the six heavy metals, and then for all six metals. The discriminant analysis results for each of the six metals are summarized in Table 1 . Assessment of the results requires examining the canonical correlation statistic, the Wilks' Lambda statistic, and the Chi-square value. The canonical correlation statistic indicates the ratio of between-group to total-variance estimates along the discriminant function. Hence, the larger the canonical correlation statistic, the greater the between-groups variation as a proportion of the total variation. The Wilks' Lambda is used to test the goodness-of-fit of the analysis. The larger the value of Wilks' Lambda, the greater is the within-groups variation as a proportion of the total, and the less successful is the discriminant function at separating the groups. A Lambda of 0.0 denotes perfect discriminatory power and a 1.0 no discriminatory power (StatSoft, 1997). The Wilks' Lambda statistic is an inverse of the F-ratio and can be transformed into a Chi-square value, and then used to test the statistical significance of the discriminant function. From Table 1 it could be noticed that the canonical correlation values range from 0.544 to 0.825 , thereby emphasizing a high degree of between-site variations for the metals under investigation. The Wilks' Lambda statistics, with the exception of those for $\mathrm{Cu}$ and $\mathrm{Pb}$, have significant values of less than 0.5 . From the summary statistics the claim could be made that distinct concentrations of heavy metals existed along the coast. To determine whether geographic areas and associated groups of metals could be distinguished along the coast, the discriminant analysis program was executed for all of the metals. Fig. 3, a plot of the first and second canonical discriminant functions for the six metals, demonstrates distinctive groupings of metal concentrations.

\section{DISCUSSION AND CONCLUSION}

The discriminant analysis results, when used in conjunction with the Box and Whisker plots, provided statistical evidence that the heavy metals were not homogeneously distributed along the coast. Distinct groups of metals were recognized, and each group could be associated with a specific sample site or a group of sample sites (i.e., geographic area) which are in proximity to each other. Group 1 includes sites 1 to 4 , an area near to the Azerbaijan border. The recent study by de Mora, et al. (2004a) reported that this area of the Caspian sea is highly polluted with toxic wastes and heavy metal contaminants discharged from the numerous oil extraction, petrochemical and industrial complexes in Azerbaijan. Group 2, comprising sites 5 and 6, is affected by a massive amount of contaminants from anthropogenic sources. The 720 km long Sefid Rud River discharges into the nearshore area of sites 5 and 6 contaminated agricultural, food processing, pulp and paper, industrial and urban wastes which have been collected from various sources located in its $67,000 \mathrm{~km}^{2}$ drainage basin. Thepollution of waterways in Iran with heavy metals from a variety of sources was discussed by Diagomanolin, et al. (2004), with the presentation of significant findings on heavy metal contamination in the Karoon River drainage basin. Moreover, the nearshore area stretching from Dastak to Gaskar mahale is comparatively shallow, and runup of high waves deposit, on a regular basis, contaminated sediments in the lower foreshore and mid-shore areas. The discriminant analysis also successfully distinguished Group 3, encompassing sites 7 to 12, a broad geographic area stretching from Tonkabon to Amirabad. 

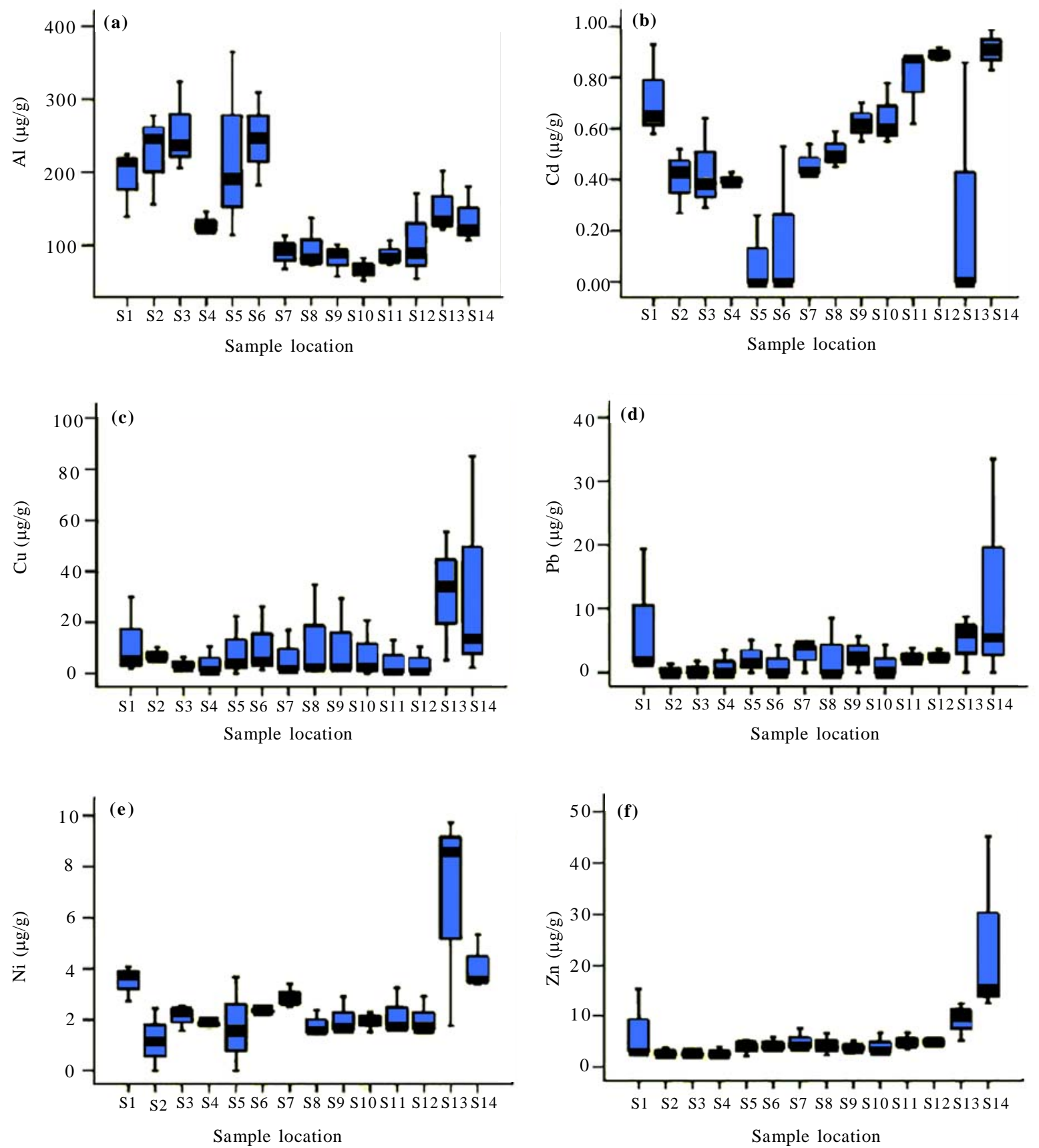

Fig. 2: Box and Whisker plots of heavy metal concentrations. The horizontal bar in the box displays the median value, the ends of the Whiskers to the maximum and minimum values. The top and bottom of the boxes include half the data points between the median and the extremes of the range 
A. Parizanganeh, et al.

Table 1: Summary of discriminant analysis results for the six heavy metals from the fourteen sample sites

\begin{tabular}{lccccc}
\hline Metals & $\begin{array}{c}\text { Canonical } \\
\text { correlation }\end{array}$ & Wilks' Lambda statistic & Chi-square & $\begin{array}{c}\text { Degrees of } \\
\text { freedom }\end{array}$ & Significance \\
\hline $\mathrm{Al}$ & 0.825 & 0.319 & 38.300 & 13 & 0.000 \\
$\mathrm{Cd}$ & 0.843 & 0.289 & 41.536 & 13 & 0.000 \\
$\mathrm{Cu}$ & 0.544 & 0.704 & 11.763 & 13 & 0.547 \\
$\mathrm{~Pb}$ & 0.547 & 0.701 & 11.886 & 13 & 0.537 \\
$\mathrm{Ni}$ & 0.759 & 0.424 & 28.782 & 13 & 0.007 \\
$\mathrm{Zn}$ & 0.768 & 0.411 & 29.821 & 13 & 0.005 \\
\hline
\end{tabular}

As shown by the Box and Whisker plots, with the exception of Cd, fairly similar median concentrations of heavy metals could be found in this group. Groups 4 and 5 represent sites 13 and 14 respectively. Both sites are near to the eastern side of the Caspian Sea. These two groups have statistically unique concentrations of all metals. The concentration of heavy metals in Group 4, representing site 13 in the vicinity of Gamishtapeh, is a direct consequence of metals being discharged from the leather and refining industries. The industrial center of Bandar-e-Torkman is a major source of polluting heavy metals around site 13 . Group 5, the specific area of site 14 that is near to Makhdomgholi, is under the influence of numerous sources of pollutants which are discharged into the nearshore area from industries by the Behshahr industrial complex. This area is becoming heavily polluted because the pollutants are not dispersed by the anti-clockwise longshore currents which become considerably slower as they reach the southeast coast of the Caspian sea. Although the correlation and regression analyses results were not in agreement with those of previous investigators (Windom, et al., 1989; Huang and Lin, 2003; Lakhan, et al., 2003) who found the grain size of sediments to be a major factor controlling the concentrations and spatial distributions of heavy metals, the discriminant analysis, nevertheless, proved useful in identifying specific sites and geographic areas where heavy metal concentrations occur along the coast. Since toxic heavy metals are discharged into the nearshore area of the Caspian sea on a daily basis, the potential exists for incremental additions of heavy metals to reach detrimental toxic concentrations at those sites and areas which are exposed to regular loadings of heavy metals.

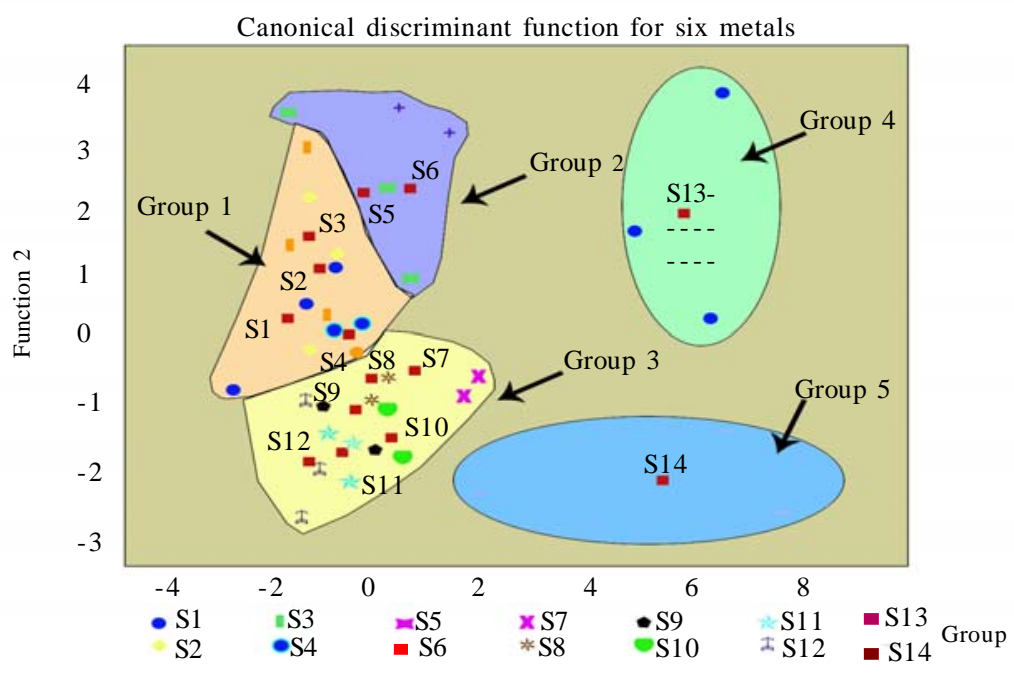

Fig. 3: Plot of the first and second canonical discriminant functions for the six heavy metals 
To prevent severe heavy toxic metal pollution of the nearshore marine areas, especially at and in the vicinity of communities exposed to anthropogenic-derived metal inputs, it becomes imperative to implement timely monitoring and remediation strategies to alleviate the loadings and cumulative concentrations of heavy metals in the nearshore marine environment.

\section{ACKNOWLEDGMENTS}

Zanjan University of Iran and University of Windsor as well as Great Lakes Institute for Environmental Research, in Windsor of Canada, are acknowledged for their financial support. Sincere thanks to Dr. Brian Fryer, Professor and Director and Mr. J.C. Barrette, Technician, Great Lakes Institute for Environmental Research, for their professional and technical assistances.

\section{REFERENCES}

Agusa, T.; Cainito, T.; Tanabe, S.; Pourkazemi, M.; Aubrey, D.G., (2004). Concentrations of trace elements in muscle of sturgeons in the Caspian Sea. Mar. Pollut. Bull., 49, 789-800. Anan, Y.; Kunito, T.; Ikemoto, T.; Kubota, R.; Watanabe, I.; Tanabe, S.; Miyazaki, N.; Petrov, E.A., (2002). Elevated concentrations of trace elements in Caspian seals (Phoca caspica) found stranded during the mass mortality events in Arch. Environ. Con. Tox., 42, 354-362.

Arujo, M.; Fatima, D.; Bernard, P.C.; Van Grieben, R.E., (1988). Heavy metal contamination in sediments from the Belgian coast and Scheldt estuary. Mar. Pollut. Bull., 19, 269-273.

Avila-Perez, P.; Garcia-Aragon, J.A.; Diaz-Delgado, C.; TejedaVega, S.; Reyes-Gutierrez, R., (2002). Heavy metal distribution in bottom sediments of a Mexican reservoir. Aqua. Eco. Health Manag., 5(2), 205-216.

Balls, P.W.; Hull, S.; Miller, B.S.; Pirie, J.M.; Proctors, W., (1977). Trace metals in Scottish estuarine and coastal sediments. Mar. Pollut. Bull., 47, 42-50.

Buchholtz ten Brink, M.; Bothner, M.H.; Manheim, F.T.; Butman, B., (1997). Contaminant metals in coastal marine sediments: A legacy for the future and a tracer of modern sediment dynamics', Proc. of the U.S. Geological Survey Sediment Workshop, 4-7 February.

Caspian Environment Programme, Caspian Sea, Environmental Issues (Iran). http:// www.caspianenvironment.org/newsite/ Caspian-EnvironmentalIssues.htm (accessed May 5, 2006).

Caccia, V.G.; Millero, F.J.; Palanques, A,. (2003). The distribution of trace metals in Florida Bay sediment. Mar. Pollut. Bull., 46(11), 1420-1433.

Cauwet, G., (1987). Influence of sedimentological features on the distribution of trace metals in marine sediments. Mar. Chem., 22, 222-234.

Çelo, V.; Babi, D.; Baraj, B.; Çullaj, A., (1999). An assessment of heavy metal pollution in the sediments along the Albanian coast. Water Air Soil Pollut., 111, 235-250.

Chakrapani, G.J.; Subramanian, V., (1993). Heavy metals distribution and fractionation in sediments of the Mahandi River basin, India. Environ. Geo., 22, 80-87.

Che, Y.; He, Q.; Lin, W.Q., (2003). The distributions of particulate heavy metals and its indication to the transfer of sediments in the Changjiang estuary and Hangzhou Bay. Mar. Pollut. Bull., 46(1), 123-131.

Chen, Z.; Saito, Y.; Kanai, Y.; Wei, T.; Li, L.; Yao, H.; Wang, Z., (2004). Low concentration of heavy metals in the Yangtze estuarine sediments, China: A diluting setting. Estuarine. Coast. Shel. Sci., 60(1), 91-100.

De Gregori, I.; Pinochet, H.; Arancibia, M.; Vidal, A., (1996). Grain-size effect of trace metals distribution in sediments from two coastal areas of Chile. Bull. Environ. Contam. Toxic Pollut., 57, 163-170.

De Mora, S.; Turner, T., (2004). The Caspian Sea: A microcosm for environmental science and international cooperation. Mar. Pollut. Bull., 48, 26-29.

De Mora, S.; Sheikholeslami, M.R.; Wyse, E.; Azemard, S.; Cassi, R., (2004a) An assessment of metal contamination in coastal sediments of the Caspian Sea. Mar. Pollut. Bull., 48, 61-77.

De Mora, S.; Villeneuve, J.P.; Sheikholeslami, M.R.; Cattini, C.; Tolosa, I., (2004b). Organochlorinated compounds in Caspian Sea sediment. Mar. Pollut. Bull., 48, 30-43.

Diagomanolin, V.; Farhang, M.; Ghazi-Khansari, M.; Jafarzadeh, N., (2004). Heavy metals (Ni, Cr, Cu) in the Karoon Waterway River, Iran. Toxicology Letters. 151, 63-68.

Din, Z.B., (1994). Natural and anthropogenic trace metal input into the coastal and estuarine sediments of the Straits of Malacca. Bull. Environ. Contam. Toxicol. 55, 666-673.

Energy Information Administration, Caspian Sea Region: Environmental Issues. February, 2003 (United States) http:/ /www.eia.doe.gov/emeu/cabs/caspenv.html\#stats (accessed May 5, 2006).

Ergin, M., (1991). Heavy metal concentrations in surface sediments from the two coastal inlets of the Northeastern Sea of Marmara. Chem. Geo., 91(3), 269.

Fatima, M., Araujo, D., Bernard, P.C. and Van Grieken, R.E. (1988). Heavy metal contamination in sediments from the Belgian coast and Scheldt estuary. Mar. Pollut. Bull., 19(6), 269-273.

Förstner, U.; Calmano, W.; Schoer, J., (1982). Metals in sediments from the Elbe, Weser and Ems estuaries and from the German Bight: Grain size effects and chemical forms. Thalassia Jugosl. 12, 30-36.

GLIER, (1996). Great Lakes Institute for Environmental Research Laboratory Manual, Revised March 22, 1996, Section 4.10, University of Windsor, Windsor, ONTARIO.

Gorenc, S.; Kostaschuk, R.; Chen, Z., (2004). Spatial variations in heavy metals on tidal flats in the Yangtze Estuary, China. Environ. Geo., 45(8), 1101-1108.

Huang, K.M.; Lin, S., (2003). Consequences and implication of heavy metal spatial variation in sediments of the Keelung River drainage basin, Taiwan. Chemosphere. 53, 1113-1121.

Huberty, C.J., (1994). Applied Discriminant Analysis. WileyInterscience, New York.

Johnston, R.J., (1992). Multivariate Statistical Analysis in Geography. John Wiley and Sons, New York.

Kajiwara, N.; Niimi, S.; Watanabe, M.; Ito, Y.; Takahashi, S.; Tanabe, S.; Khuraskin, L.S.; Miyazaki, N., (2002). Organochlorine and organotin compounds in Caspian seals (Phoca caspica) collected during an unusual mortality event in the Caspian Sea in 2000. Environ. Pollut., 117, 391-402.

Kajiwara, N.; Ueno, D.; Monirith, I.; Tanabe, S.; Pourkazemi, M.; Aubrey, D.G., (2003). Contamination by organochlorine compounds in sturgeons from Caspian Sea during 2001 and 
A geochemical and statistical approach for assessing heavy metal...

2002. Mar. Pollut. Bull., 46, 741-747.

Lakhan, V.C.; Cabana, K.; LaValle, P.D., (2002). Heavy metal concentrations in surficial sediments from accreting and eroding areas along the coast of Guyana. Environ. Geo., 42, 73-80.

Lakhan, V.C.; Cabana, K.; LaValle, P.D., (2003). Relationship between grain size and heavy metals in sediments from beaches along the coast of Guyana. J. Coast. Res., 19 (3), 600-608.

Lin, S.; Hsieh, I.J.; Huang, K.M.; Wang, C.H., (2002). Influence of the Yangtze River and grain size on the spatial variations of heavy metals and organic carbon in the East China Sea continental shelf sediments. Chem. Geol., 182, 377-394.

Maurer, D.; Robertson, G.; Gelinger, T., (1994). Trace metals in the Newport Submarine Canyon, California and the adjacent shelf. Water Environment Research. 66 (2), 110-118.

McLachlan, G.J., (2004). Discriminant Analysis and Statistical Pattern Recognition. Wiley-Interscience, New York.

McMurtry, G.M.; Wiltshire, J.C.; Kauhikaua, J.P., (1995). Heavy metal anomalies in coastal sediments of O'ahu Hawaii. Pacific Sci., 49(4), 452-470.

Motavalli, J., (1999). Black gold-Caspian Sea oil development. Environ. Manage., 10(6).

Neville, R., (2006). Environmental Protection in the Caspian Sea: Policy Constraints and Prescriptions. International Institute for Caspian Studies. http://www.caspianstudies.com/ article/Rachel Nevil.htm (accessed May 4, 2006)

Ryan, J.D.; Windom, H.L., (1988). A geochemical and statistical approach for assessing metal pollution in coastal sediments. In Metals in Coastal Environments of Latin America. Springer, Berlin, Heidelberg, New York, 47-58.

Santos, I.R.; Silva-Fiho, E.V.; Schaefer, C.E.G.R.; AlbuquerqueFilho, M.R.; Campos, L.S., (2005). Heavy metal contamination in coastal sediments and soils near the Brazilian Antarctic Station, King George Island. Mar. Pollut. Bull., 50(2), 185-194.
Statistical Package for the Social Sciences (SPSS, Inc.), (2003). Version 13 for Windows. SPSS, Inc., Chicago, IL.

StatSoft, Inc., (1997). Statistica for Windows (Computer Program Manual). StatSoft, Inc., Tulsa, OK.

Subramanian, V.; Mohanachandran, G., (1990). Heavy metals distribution and enrichment in the sediments of the southern east coast of India. Mar. Pollut. Bull., 21(7), 324-330.

Tolosa, I.; de Mora, S.J.; Sheikholeslami, M.R.; Villeneuve, J.P.; Bartocci, J.; Cattini, C., (2004). Aliphatic and aromatic hydrocarbons in coastal Caspian Sea sediments. Mar. Pollut. Bull., doi:10.1016/S0025-326X(03)00255-8.

Ujevic, I.; Odzak, N.; Baric, A., (2000). Trace metal accumulation in different grain size fractions of the sediments from a semi-enclosed bay heavily contaminated by urban and industrial wastewaters. Water Res., 34(11), 3055-3061.

Uriarte, A.; Franco, J.; Borja, A.; Valencia, V.; Castro, R., (1998). Sediment and heavy metal distribution and transport in a coastal area affected by a submarine outfall in the Basque Country (Northern Spain). Water Sci. Tech., 37(6-7), 55-61.

Windom, H.L.; Schropp, S.J.; Calder, F.D.; Ryan, J.D.; Smith Jr., R.G.; Burney, L.C.; Lewis, F.G.; Rawlinson, C.H., (1989). Natural trace metal concentrations in estuarine and coastal marine sediments of the southeastern United States. Environ. Sci. Technol., 23, 314-320.

Zabetoglou, K.; Voutsa, D.; Samara, C.. (2002). Toxicity and heavy metal contamination of surficial sediments from the Bay of Thessaloniki (Northwestern Aegean Sea) Greece. Chemosphere. 49, 17-26.

Zhang, W.; Yu, L.; Hutchinson, S.M.; Xu, S.; Chen, Z.; Gao, X., (2001). China's Yangtze Estuary: 1. Geomorphic influence on heavy metal accumulation in intertidal sediments. Geomorphology, 41(2-3), 195-205.

\section{AUTHOR (S) BIOSKETCHES}

Parizanganeh, A. H., B.Sc., M.Sc., Ph.D. Is a lecturer in the Department of Geography, Zanjan University, Iran. Email: zanganeh_h@yahoo.com

Lakhan, V. C., Ph.D. (Toronto) F.R.G.S. (UK), C.E.I. (US), C.E.S. (US) is a Professor in the Earth Sciences Department at the University of Windsor, Ontario, Canada. Email: lakan@uwindsor.ca

Jalalian, H., Ph.D. Is a lecturer in the Department of Geography, Zanjan University, Iran.

Email: hamjalal1970@yahoo.com

This article should be referenced as follows:

Parizanganeh, A. H., Lakhan, V. C., Jalalian, H., (2007). A geochemical and statistical approach for assessing heavy metal pollution in sediments from the southern Caspian coast . Int. J. Environ. Sci. Tech., 4 (3), 351-358. 